\title{
VARIEDADES Y VARIACIONES DE CAPITALISMO EN LA PERIFERIA. AMÉRICA LATINA Y EL ESTE ASIÁTICO RECONSIDERADOS*
}

\author{
Recibido: 30 de mayo de 2016 • Aprobado: 01 de agosto de 2017 \\ DOI: 10.22395/seec.v20n45a3
Víctor Ramiro Fernández ${ }^{* *}$
Alcides Bazza**
Cristhian Seiler ${ }^{* * *}$

\section{RESUMEN}

El artículo propone un marco analítico alternativo al enfoque institucional de variedades de capitalismo para comprender la divergente emergencia y dinamismo industrial entre el Este Asiático y América Latina en el denominado Sur Global. El carácter alternativo se fundamenta en el distanciamiento del tratamiento nacionalista metodológico y focalizado en las complementariedades institucionales identificadas en países desarrollados -propio de este enfoque-, para considerar las características que identifican a países en contextos periféricos, y los cambios temporales y espaciales en estos. Se introduce las nociones de "núcleo de acumulación" y "núcleo de implicación estatal" como herramientas teóricas alternativas que consideran tal condición periférica -y sus cambios-, entendiendo los procesos de acumulación y los Estados que conforman las macro-regiones analizadas en una relación dialéctica e ínter-penetrante con permisividades externas y viabilidades internas.

\section{PALABRAS CLAVE}

Desarrollo económico; planeación del desarrollo y políticas; variedades de capitalismo; núcleo de acumulación; núcleo de implicación estatal; Este Asiático; América Latina.

\section{CLASIFICACIÓN JEL}

O10, O20, 057

\section{CONTENIDOS}

Introducción; 1. Los núcleos como conceptos explicativos de trayectorias macro-regionales diferenciadas; 2. El desarrollo del Este Asiático y América Latina; 3. Los cambios en la fase global del capitalismo: desde las respuestas diferenciadas a la (in)sostenibilidad en las propiedades de los núcleos; 4. Conclusiones; Bibliografía.

\footnotetext{
Este trabajo es resultado de proyectos enmarcados en el Grupo de Investigación Desarrollo, Estado y Políticas Públicas del Instituto de Humanidades y Ciencias Sociales del Litoral (CONICET-UNL) y las discusiones en torno a las variedades de capitalismo con el Dr. Matthias Ebenau, profesor de la Universidad de Kassel, Alemania.

* Abogado, Universidad Nacional del Litoral (UNL), Santa Fe, Argentina. Máster en Ciencias Sociales (Orientación Sociología), Facultad Latinoamericana de Ciencias Sociales (Flacso), Buenos Aires, Argentina. Doctor en Ciencias Políticas, Universidad Autónoma de Madrid, España. Posdoctorado, Department of Geography, Centre for the Study of Cities and Regions, Universidad de Durham, Reino Unido. Director del Instituto de Humanidades y Ciencias Sociales del Litoral (IHuCSo Litoral), Santa Fe, Argentina. Profesor de la Facultad de Humanidades y Ciencias (FHUC), Universidad Nacional del Litoral, Santa Fe, Argentina. Dirección: Pedro Díaz Colodrero 2462, CP: 3000. Tel: +54 (0342) 4575140. Correo: rfernand@fcjs.unl.edu.ar

... Abogado, Universidad Católica de Santa Fe, Santa Fe, Argentina. Especialista en Derecho de la Empresa, Universidad Nacional del Litoral, Santa Fe, Argentina. Doctorando en Ciencias Políticas, Universidad Nacional de Rosario, Santa Fe, Argentina. Investigador del Instituto de Humanidades y Ciencias Sociales del Litoral, Santa Fe, Argentina. Profesor, Facultad de Ciencias Jurídicas y Sociales, Universidad Nacional del Litoral, Santa Fe, Argentina. Tel: +54 (0342) 4575140. Dirección: Francia 2357, Piso 3 - Dpto. C, CP: 3000 . Correo: alcidesbazza@gmail. $\underline{\text { com }}$

... Licenciado en Ciencia Política y Doctorando en Ciencias Sociales, Universidad Nacional de Entre Ríos, Paraná, Argentina. Investigador del Instituto de Humanidades y Ciencias Sociales del Litoral, Santa Fe, Argentina. Profesor, Facultad de Ciencias Jurídicas y Sociales, Universidad Nacional del Litoral, Santa Fe, Argentina. Tel: +54 (0343) 5327057. Dirección: San Lorenzo 3128, Piso 3 - Dpto. A, CP: 3000 Correo: cristhianseiler@gmail.com
} 


\title{
VARIETIES AND VARIATIONS OF CAPITALISM ON THE PERIPHERY. LATIN AMERICA AND EAST ASIA REVIEWED
}

\begin{abstract}
The paper proposes an alternative analytical framework to the institutional approach of varieties of capitalism in order to understand the divergent emergence and industrial dynamism between East Asia and Latin America in the so-called Global South. The alternative character is based on the distancing of the methodological nationalist treatment and focused on the institutional complementarities identified in developed countries -specific to this approach-, to consider the characteristics that identify countries in peripheral contexts, and the temporal and spatial changes in these. The notions of "accumulation nucleus" and "state implication nucleus" are introduced as alternative theoretical tools that consider this peripheral condition -and its changes-, understanding the accumulation processes and the states that make up the macro-regions analyzed in a dialectical and inter-penetrating relationship with external permissiveness and internal feasibility.
\end{abstract}

\section{KEYWORDS}

Economic development; development planning and politics; varieties of capitalism; nucleus of accumulation; nucleus of state involvement; East Asiatic; Latin America.

\section{JEL CLASSIFICATION}

O10, O20, O57

\section{CONTENT}

Introduction; 1 . The nuclei as explanatory concepts of differentiated macro-regional paths; 2 . The development of East Asia and Latin America; 3. Changes in the global phase of capitalism: from differentiated responses to unsustainability in core properties; 4. Conclusions; Bibliography

\section{VARIEDADES E VARIACCÕES DE CAPITALISMO NA PERIFERIA. AMÉRICA LATINA E LESTE ASIÁTICO RECONSIDERADOS \\ RESUMO}

Este artigo propõe um referencial analítico alternativo à abordagem institucional de variedades de capitalismo para compreender a divergente emergência e dinamismo industrial entre o Leste Asiático e a América Latina no denominado Sul Global. O caráter alternativo se fundamenta no distanciamento do tratamento nacionalista metodológico e focado nas complementaridades institucionais identificadas em países desenvolvidos — próprio dessa abordagem — , para considerar as características que identificam países em contextos periféricos e as mudanças temporais e espaciais nestes. São introduzidas as noções de "núcleo de acumulação" e "núcleo de envolvimento estatal" são introduzidas como ferramentas teóricas alternativas que consideram a condição periférica - e suas mudanças - entendendo os processos de acumulação e os Estados que conformam as macrorregiões analisadas numa relação dialética com permissividades externas e viabilidades internas.

\section{PALAVRAS-CHAVE}

Desenvolvimento econômico; planejamento e políticas de desenvolvimento; variedades do capitalismo; núcleo de acumulação; núcleo de envolvimento estatal; Leste Asiático; América Latina.

\section{CLASSIFICAÇÃO JEL}

O10, O20, 057

\section{CONTEÚDOS}

Introdução; 1. Os núcleos como conceitos explicativos de trajetórias macrorregionais diferenciadas; 2. O desenvolvimento do Leste Asiático e da América Latina; 3. As mudanças na fase global do capitalismo: das respostas diferenciadas à (in)sustentabilidade nas propriedades dos núcleos; 4. Conclusões; Bibliografia. 
Variedades y variaciones de capitalismo en la periferia. América Latina y el este asiático reconsiderados

\section{INTRODUCCIÓN}

En las últimas dos décadas, se ha hecho visible la gestación de un nuevo ordenamiento geopolítico y geoeconómico del sistema capitalista dado por un debilitamiento de la capacidad hegemónica norteamericana y, centralmente, producto de la visible emergencia de un nuevo centro dinámico que se ha denominado Sur

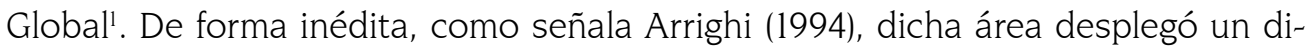
namismo industrial y económico de magnitudes similares a los países centrales agrupados en el Norte.

Sin embargo, en su interior, ese dinamismo no ha sido homogéneo en términos de la intensidad del crecimiento productivo en general, particularmente, respecto a las formas que adquirió la dinámica industrial. Mientras que los países del Este Asiático (EA), a partir de un proceso macro-regional, mediado por el papel de distintivos espacios nacionales, consolidaron un mayor dinamismo industrial global (primero a través de Japón y luego, a partir de 1990, con la avasallante irrupción de China), que no tuvo correlato equiparable con los países de América Latina (AL).

La formación de esta divergencia en el Sur Global se presenta como un relevante campo de reflexión para indagar con mayor precisión teórica dos aspectos de destacada importancia. En primer lugar, dar cuenta sobre cuáles fueron los elementos fundamentales que permitieron que algunas experiencias nacionales del EA, agrupadas en macro-regiones, alteraran la condición periférica (como son Japón, Corea del Sur, a la que podría incluirse, Taiwán) o bien desafiaran el sistema monopolar² (como es el caso de China). Y, por otra parte, determinar cómo y por qué la ausencia de tales elementos reforzó la condición periférica de AL, la que se mantuvo inalterada, y reforzó su calificativo como región más desigual del planeta.

El análisis de estos aspectos requiere una reelaboración del instrumental analítico que considere las variedades de capitalismo en la periferia, debido a que el enfoque dominante de las "complementariedades institucionales" centrado en Hall y Soskice (2001), no considera tanto la relación centro-periferia -como una variedad específica dentro de las lógicas de acumulación capitalistas-, como las variaciones en la periferia. Como señalan Peck y Theodore (2007) y Fernández y Alfaro (2011), los análisis mono-escalarmente centrados en exámenes nacionales, situados en los países centrales, y con una tendencia estática que no identifica los cambios temporales y espaciales, colaboraron en la replicación de su batería analítica

\footnotetext{
1 En la academia anglosajona y en la acción política institucional del "centro", la noción de Sur Global o "periferia" (la que utilizaremos indistintamente) es un concepto emergente que no se parangona con las fronteras geográficas sino que hace referencia a las históricas y/ o actuales divisiones de trabajo y riqueza que han llevado al desarrollo desigual y a las divisiones socio-espaciales que se construyen a través de este proceso.

2 Marcado por la hegemonía norteamericana desde la fase monopólica del capitalismo.
} 
en la periferia. No obstante que trabajos como los de Schneider y Soskice (2009), Schneider $(2013,2009)$ y Boschi (2011) realizaron adaptaciones y ampliaciones críticas, en lo sustancial continuaron con problemas para reconocer la especificidad periférica, así como los factores neurálgicos implicados en las diferencias en tal condición ${ }^{3}$.

En función de ello, el trabajo propone un abordaje teórico alternativo que supla las deficiencias del enfoque mainstream de variedades de capitalismo, y brinde respuestas sobre los dos aspectos antes mencionados. Con este objetivo, se introducen los conceptos de núcleo de acumulación y núcleo de implicación estatal como puentes explicativos de las trayectorias divergentes entre las macro regiones del sur global (EA y AL). Ambos conceptos permiten advertir: por un lado, los fundamentos económicos e institucionales que sostienen la variable capacidad y autonomía para alterar el posicionamiento periférico de las trayectorias nacionales y / o macro-regionales; y, por otro lado, escapar al análisis mono-escalar y estático del enfoque de variedades de capitalismo, al considerar la dinámica inestable y cambiante de esas trayectorias, a raíz de las permisividades externas y viabilidades internas propias de los procesos históricos y espaciales en la construcción de esos núcleos. Así se destaca, tanto en las experiencias del EA como de AL, la penetrante actuación de las redes económicas y políticas globales en la actual fase del capitalismo, y frente a ello, la diferencial capacidad inmunológica de los núcleos consolidados en ambas macro-regiones para viabilizar el desarrollo.

El trabajo se desarrolla en tres secciones. La primera introduce los aspectos teóricos de los núcleos de acumulación y núcleos de implicación estatal, a través de la identificación de sus propiedades principales, y su interrelación con las dinámicas internas y externas. Sobre la base conceptual presentada, con referencia al EA y AL, la segunda sección profundiza comparativamente la constitución y dinamismo entre los núcleos desde la segunda posguerra. La tercera sección pone atención en la sostenibilidad de la propiedad de los núcleos con especial foco en el EA en la fase actual del capitalismo. Finalmente, se concluye con la mención de los aportes analíticos.

\footnotetext{
3 Debido a razones de espacio en este trabajo, un desarrollo más extenso y detallado de las críticas y debilidades que presenta el enfoque de variedades de capitalismo para dar cuenta de las especificidades y condiciones periféricas, el lector puede dirigirse a trabajos como los de Fernández y Bazza (2016), Fernández y Alfaro (2011), o Fernández (2010). Solo en términos generales, el enfoque alternativo que propone este trabajo se distancia de la noción de "complementariedades institucionales" (centrada en los modelos de Economías de Mercado Coordinado -EMC- y Economías de Libre Mercado -ELM-) destacando que las variedades capitalistas son condicionadas no solo por aspectos resultantes entre la dinámica interna y externa, sino también por la dinámica contradictoria de la matriz capitalistas. Como será desarrollado a lo largo del trabajo, el enfoque propuesto contiene y/o parte de considerar que las trayectorias de desarrollo poseen un carácter estructural y contradictorio intrínseco a la dinámica del capitalismo (Jessop, 2015).
} 
Variedades y variaciones de capitalismo en la periferia. América Latina y el este asiático reconsiderados

\section{LOS NÚCLEOS COMO CONCEPTOS EXPLICATIVOS DE TRAYECTORIAS MACRO-REGIONALES DIFERENCIADAS}

Dar cuenta de los fundamentos y las condiciones que explican la divergencia -y en buena medida la excepcionalidad- de las dinámicas geoeconómicas y geopolíticas en el Sur Global demanda identificar qué elementos económicos e institucionales y estrategias de los agentes -en relación a esos elementos- les permiten operar diferencialmente en las estructuras globales, es decir, con variable capacidad para alterar el posicionamiento periférico.

Las particulares estrategias en relación con esos elementos (económicos e institucionales), en el marco de una determinada trayectoria histórica, conforma(n) una(s) variable(s) autonomía(s) de los agentes posicionados periféricamente que fundamenta su capacidad de respuesta ante el escenario contradictorio que marcan las relaciones centro-periferia y las lógicas de flujos y territorios, es decir, capacidad de respuesta frente a las estrategias de los actores exógenos. Como señalan los trabajos de Dicken (2011), Levy (2008), Cox (1987) y Carroll y Carson (2003), estos actores no operan aisladamente sino que conforman un entramado de redes económicas globales controladas por las empresas trasnacionales, pero en la que participan otros actores económicos (empresas domésticas, pymes, entre otros), en directa vinculación con los organismos internacionales, bilaterales y / o de alcance global (Global Economic Forum, World Bank, FMI, entre otros, en adelante organismos internacionales) como actores que comandan las redes políticas globales.

De esta manera, la autonomía que brinda capacidad para desarrollar esos cambios se estructura en un conjunto de elementos esenciales y realimentadores que refieren directamente a los núcleos de acumulación, como aquellas formas específicas en que los procesos de acumulación son constituidos en un espacio económico determinado, y los núcleos de implicación estatal, que apuntan a las características específicas de los Estados y las formas de implicación en los aludidos procesos de acumulación.

Lejos del aislamiento analítico nacional y de la des-historización, las propiedades de esos núcleos se han definido diferenciadamente en la periferia como resultado de las particularidades que presentan las permisividades externas y las viabilidades internas. Así, mientras las permisividades aluden a la habilitación geopolítica para el despliegue histórico de determinados procesos, y resulta -como destacaba Jaguaribe (1979)- un elemento imprescindible al momento de analizar una trayectoria de desarrollo ${ }^{4}$, las viabilidades internas son construidas sobre la base de deter-

4 En tal sentido, como señala Medeiros (2010), buena parte de la literatura desarrollista -y en particular del Estado desarrollista-mostró como una de sus visibles limitaciones la asunción de una perspectiva metodológicamente 
minadas trayectorias históricas en la conformación de los núcleos de acumulación y núcleos de implicación estatal, las que mantienen una estrecha vinculación con las permisividades externas.

Como mencionamos, en tanto ambos núcleos operan re-alimentariamente, las propiedades de cada uno y sus relaciones conllevan implicancias para el otro núcleo y sus propiedades, y la forma como esa relación dialéctica se desenvuelve en determinados procesos históricos y espacios configura, en la periferia, los fundamentos de las particulares variedades de capitalismo. Este punto es de especial relevancia para entender la propuesta alternativa que plantea este trabajo respecto al enfoque mainstream de Variedades de Capitalismo.

Tabla 1: Propuesta alternativa al análisis mainstream de variedades de capitalismo

\begin{tabular}{|c|c|}
\hline Enfoque de variedades (mainstream) & Variedades desde la periferia \\
\hline - Variedad bipolar EMC y ELM & - Variedad bipolar centro-periferia \\
\hline $\begin{array}{l}\text { - Carácter estático funcional: au- } \\
\text { sencia de los cambios }\end{array}$ & $\begin{array}{l}\text { - Cambios alcance estratégico: capacidad diferen- } \\
\text { cial de abandonar el posicionamiento periférico }\end{array}$ \\
\hline $\begin{array}{l}\text { - Nacionalismo metodológico: mo- } \\
\text { delo monoescalar }\end{array}$ & $\begin{array}{l}\text { Espacios periféricos y arreglos institucionales } \\
\text { atravesados por los flujos de redes que procuran } \\
\text { el fortalecimiento de las relaciones de subordina- } \\
\text { ción }\end{array}$ \\
\hline $\begin{array}{l}\text { - El Estado como un elemento más } \\
\text { del complejo regulatorio }\end{array}$ & $\begin{array}{l}\text { - El Estado como instancia regulatoria específica y } \\
\text { distintiva, junto a la fuerza de trabajo en las tra- } \\
\text { yectorias diferenciadas }\end{array}$ \\
\hline
\end{tabular}

Fuente: elaboración propia

Así, el núcleo de acumulación se configura a partir de cuatro aspectos / variables relevantes, y sus respectivas dimensiones y efectos, a su vez, sobre las dimensiones externas (que escapan al marco analítico del enfoque de variedades de capitalismo) e internas de los espacios nacionales. Estos aspectos / variables consisten en:

- El origen y forma de control del capital que domina el ciclo de industrialización y la forma de integración del capital trasnacional al proceso nacional de acumulación. Importa aquí considerar si el complejo de actividades de mayor di- 
namismo y generación o retención de valor, así como los actores vinculados a esas actividades se localizan dentro de un determinado espacio nacional, o si, por el contrario, esas actividades u actores resultan externas. De ello pende la configuración de un núcleo de acumulación dominantemente endógeno u exógeno, donde opera el dominio trasnacional en los sectores más relevantes o, bien, el control de dichos sectores queda subordinado a la gestación endógena de las firmas.

- La segunda variable, en estrecho vínculo con la primera, se relaciona con el origen y control del sistema financiero. En este sentido, la mayor endogeneidad de las finanzas locales permite a los Estados una mayor capacidad para dirigir el destino de los mismos; mientras que, por el contrario, la exogeneidad / extranjerización de las finanzas condiciona a los Estados en el uso de los ahorros realizados en el sistema financiero.

- La forma dominante de reproducción del capital. Aquí se distingue aquellas dinámicas fundadas en la generación de plusvalías a través de los procesos de aprendizaje e innovación, de aquellas estáticas centradas en las cuasi-rentas provenientes de la capitalización de ventajas comparativas naturales que otorgan rentas selectivas. Mientras en las anteriores dimensiones, como indicamos, el núcleo de acumulación asume formas alternativas dominantemente endógenas o exógenas, a partir de este se define su carácter dinámico o rentista.

- El nivel de articulación del capital financiero con el productivo a partir de formas de valorización desplegadas en el sistema financiero y escasa o relativa conexión con el sistema productivo, o condicionadas por el comportamiento de -y la vinculación a- este último. Esta variable actúa como un vector condicionante para la conformación de las otras antes indicadas: así, una auto-reproducción del capital financiero con una articulación débil con el sistema productivo, en los escenarios periféricos limita la capacidad de impulsar un patrón productivo más endógeno y, a su vez, dinámico, en el que puedan financiarse extensivamente los procesos de aprendizajes e innovación.

Sobre la base de estos cuatro elementos emergen las características de los núcleos de acumulación que afectan el hacia adentro y hacia afuera de los espacios nacionales. Hacia el interior, los efectos distributivos del patrón productivo endógeno y la extensión de la dinámica del conocimiento se traducen internamente en un patrón productivo más complejo y homogéneo en relación con la productividad y los ingresos, y por tanto más homogéneo socialmente. Por su parte, un proceso 
de acumulación dominado por un carácter exógeno y aferrado a las rentas naturales conforma un patrón productivo menos denso y una estructura social más desigual y heterogénea. Hacia el exterior -como aspecto desconsiderado en el análisis de variedades de capitalismo-, la forma endógena / exógena o rentista / dinámica del núcleo de acumulación impacta y condiciona el patrón de inserción internacional obtenido. La inserción por las vías altas de las redes económicas globales, es decir, en aquellos segmentos de más alta valorización, se halla inevitablemente ligada al dominio de un patrón endógeno y dinámico, mientras que la preponderancia de un control exógeno asociado a formas de valorización rentistas (sin innovación) alienta una inserción subalterna en los segmentos / funciones de más baja valorización.

En su conformación y cambio, estas propiedades - con sus efectos intra y extra nacionales- están afectadas por las calidades desarrolladas por el núcleo de implicación estatal. En tal sentido, Arrighi (1994) sostiene que los Estados no solo adquieren un papel fundamental en el despliegue de la lógica global de acumulación y la conformación histórica de los centros de hegemonía cíclica del capitalismo, sino que sus calidades y funciones estratégicas se vuelven relevantes en la determinación de las especificidades de los núcleos de acumulación que se configuran en las distintas trayectorias nacionales -y macro regionales-. Esas calidades, históricamente configuradas, se definen en este caso a partir de cuatro grandes variables:

- La calidad de la estructura organizacional, entendida a partir de dos dimensiones fundamentales e interrelacionadas: a) la base conceptual / operativa, y b) las formas de reclutamiento del staff burocrático. Al indagar, se distinguen dos tipos básicos de configuraciones estatales: por un lado, aquellas en las que prima la formación de un staff político-burocrático cuya perspectiva conceptual se orientó a la implementación de estrategias que priorizan el desarrollo endógeno y competitivo de la estructura productivo / industrial acompañado de un proceso meritocrático de reclutamiento, basado en la selección de los mejores, acorde con su formación y pertinencia con los objetivos; por otro lado, aquellas configuraciones estatales en cuyo staff prepondera una base conceptual y operativa ligada a la cobertura de demandas de actores endógenos y exógenos, así como formas de reclutamiento ajenas a la valoración de la idoneidad y competencia de los servidores civiles.

- La presencia de instancias estatales piloto o nodales que articulan internamente las estructuras y flujos de acción del Estado, para cohesionar y dirigir su implicación hacia el proceso de industrialización y acumulación; o bien 
su ausencia, es decir, configuraciones donde dominan las formas intra-estatales predominantemente fragmentadas y distantes de una organización coherente.

- La existencia o inexistencia de control o capacidad estatal para dirigir el financiamiento a los procesos de producción / industrialización, de lo que deriva la subordinación del capital financiero a las estrategias productivas orientadas por el Estado.

- La presencia o ausencia de control del capital concentrado y de la organización del trabajo y la sociedad civil para constituirse como coaliciones sociales que dan soporte a la estrategia agregada de intervención estatal en relación con el núcleo de acumulación.

Ahora bien, los elementos constitutivos de los núcleos y sus propiedades tienen un vínculo dialéctico entre sí, donde la configuración de las propiedades de los núcleos de acumulación condiciona fuertemente las formas o propiedades asumidas por el núcleo de implicación estatal, y viceversa. Asimismo, ese proceso dialógico y co-determinado de ambos núcleos y sus propiedades arrastran efectos directos en la forma como las trayectorias nacionales se articulan a las redes económicas y políticas globales. Es decir, esta forma: a) en algunos casos puede operar como centros de respuestas con capacidad de condicionar la vinculación a esas redes y los actores trasnacionales que las controlan; y b) en otros casos como centros de acoplamiento, subordinados a las condiciones de selección que imponen desde esas redes sus actores controlantes y sus lógicas financieras dominantemente financieras.

La relación entre los núcleos y las redes tiene un dinamismo constante, lo que explica la variable autonomía existente en las diferenciadas trayectorias nacionales. Así, existe una relación sinérgica entre los núcleos respecto a las redes que repercute virtuosa o negativamente a través de permisividades externas y viabilidades internas para conformar los mencionados centros de respuesta o centros de acoplamiento.

Veremos a continuación, cómo esta teoría de los núcleos brinda importantes elementos explicativos respecto a las diferenciadas trayectorias del EA y AL, que escapan al enfoque teórico de las variedades de capitalismo. 
Tabla 2. Núcleo de acumulación y núcleo de implicación estatal

\begin{tabular}{|c|c|}
\hline Núcleo de acumulación & Núcleo de implicación estatal \\
\hline $\begin{array}{l}\text { Forma de generación, apropiación y distribución } \\
\text { del excedente }\end{array}$ & $\begin{array}{l}\text { Calidades para la configuración del nú- } \\
\text { cleo de acumulación }\end{array}$ \\
\hline Hacia adentro & - Estructuras estatales (organización \\
\hline $\begin{array}{l}\text { - Origen y forma del capital (endógeno-exóge- } \\
\text { no, concentrado-desconcentrado). }\end{array}$ & $\begin{array}{l}\text { meritocrática o patrimonial). } \\
\text { - } \text { Forma conceptual-operativa del staff. }\end{array}$ \\
\hline $\begin{array}{l}\text { - Origen y control del sistema financiero (endó- } \\
\text { geno-exógeno). }\end{array}$ & $\begin{array}{l}\text { - Instancias de coherencia o de frag- } \\
\text { mentación intraestatal. }\end{array}$ \\
\hline - Forma de valorización del capital productivo & $\begin{array}{l}\text { - Tipo de control y direccionamiento } \\
\text { estatal del financiamiento. }\end{array}$ \\
\hline $\begin{array}{l}\text { ventajas naturales). } \\
\text { _ } \quad \text { Nivel de articulación entre el capital financie- } \\
\text { ro con el capital productivo. }\end{array}$ & $\begin{array}{l}\text { - Nivel de control del capital corpora- } \\
\text { tivo y organizaciones del trabajo y la } \\
\text { sociedad civil. }\end{array}$ \\
\hline Hacia afuera & \\
\hline $\begin{array}{l}\text { - Forma de inserción internacional de los pro- } \\
\text { cesos de producción (vías altas de mayor va- } \\
\text { lorización o vías bajas de los recursos natu- } \\
\text { rales). }\end{array}$ & \\
\hline
\end{tabular}

Fuente: elaboración propia

\section{EL DESARROLLO DEL ESTE ASIÁTICO Y AMÉRICA LATINA}

Al abordar las experiencias del EA y AL en una perspectiva comparada para analizar desde el interior de la periferia el papel de los núcleos en la explicación alternativa de las variedades de capitalismo, se abren tres interrogantes que trataremos de abordar secuencialmente:

a. ¿Cómo intervienen esos núcleos, sus propiedades e interrelaciones, en el desarrollo de las diferentes trayectorias nacionales sobre los que se conformaron esos escenarios macro-regionales del EA y AL?

b. ¿Cuáles son las condiciones externas e internas, particularmente durante la fase monopólica y el paradigma fordista-keynesiano, que actuaron en la viabilidad u obstaculización de la formación de esos núcleos y sus relaciones en esos escenarios?

c. ¿Cómo han incidido las especificidades de esos núcleos en las repuestas nacionales y macro-regionales a la fase globalizada del capitalismo y cuál ha 
Variedades y variaciones de capitalismo en la periferia. América Latina y el este asiático reconsiderados

sido la sostenibilidad de esas respuestas -y esos núcleos, con sus propiedades y relaciones-?

\subsection{La formación diferencial de los núcleos y sus relaciones con las trayectorias nacionales y macro-regionales en la fase monopólica}

La introducción de los núcleos - con sus respectivas propiedades y sus interrelaciones- permite que, no obstante las especificidades de las trayectorias nacionales que forman los grandes escenarios del Sur Global, puedan reconocerse aquellas regularidades que han permitido selectivamente a un grupo de países - del EA-abandonar la condición periférica, así como dar contenidos claramente divergentes a los procesos de integración y desarrollo macro-regional del EA y AL. Sin embargo, como destacaremos, la existencia de esas regularidades en las trayectorias nacionales de dichos escenarios no viene dada sino que responde a un conjunto de elementos contextuales (internos y externos) que viabilizan la presencia e interrelación de los núcleos. Especificidades históricas y procesos exógenos desafían la interpretación sincrónica y descontextualizada por el nacionalismo metodológico que domina el enfoque de variedades de capitalismo.

En el EA, Gereffi (1989) indica que el proceso que guio su exitoso recorrido de desarrollo (a partir de las experiencias centrales de Japón, Corea y Taiwán) estuvo centrado en la articulación de un proceso de industrialización local por sustitución de importaciones con una inserción externa dinámica. Siguiendo a Doner (2009), su concreción implicó el paso triunfante por el estrecho corredor que se abre entre un proteccionismo ineficiente, que desarrolla una matriz endógena de actores con propensión rentista y escasa capacidad de inserción externa en actividades de alta valorización, y una industrialización sustentada en enclaves sin inserción en el tejido productivo local, donde la matriz exógena de actores y sus centros de actividades y sectores dinámicos guardaba escasa vinculación con el tejido productivo local.

Como estipula Amsden $(1989,2007)$, desde la segunda posguerra en el caso de Japón, y con posterioridad en Corea del Sur y Taiwán en la década de 1960, tuvo lugar un proceso de (re)construcción de los actores capitalistas locales, basado en una protección condicionada al desarrollo de determinados performances productivos y de una específica inserción externa. Ello implicaba pasar desde las fases sustitutivas más simples a las complejas a partir de un proceso constante de aprendizaje e innovación que viabilizó la extensión de los encadenamientos productivos y alcanzó los segmentos más dinámicos -y de más alta valorización- de esos encadenamientos. De ello resultó un núcleo de acumulación, a la vez, endógeno y di- 
námico que permitió cubrir dos aspectos esenciales del desarrollo marcados por Prebisch (1986, 1981):

i. Un posicionamiento progresivo y más poderoso de actores capitalistas locales en las funciones de alta valorización dentro de las cadenas globales, como lo muestran Blyde (2014) y Doner (2009);

ii. Y una estructura productiva más compleja e internamente articulada que combinó el crecimiento de productividad, ingresos y niveles de empleo, y favoreció estructuras sociales caracterizadas por una mayor integración, bajos niveles de informalidad laboral y, según indican Jomo (2006) y Cheng y Gereffi (1994), menores niveles de desigualdad.

Sustentados en ese núcleo de acumulación -y esos resultados-, los trabajos de Akamatsu (1962, 1961), Kasahara (2004) y Ozawa $(2011,2002)$ indican que en torno a esos tres países se logró conformar un proceso de integración macro-regional que, bajo la forma denominada como el vuelo de los gansos (flying geese), sumó nuevos adeptos de la región que configuraron la denominada Association of Southeast Asian Nations ${ }^{5}$. Sin embargo, aunque estos desarrollaron progresivamente mecanismos de sustitución de importaciones que permitieron el desarrollo del sector manufacturero y sus exportaciones, los mismos se basaron centralmente en acciones de empresas extranjeras, que conformaron una estructura económica dual compuesta por estas últimas y actuaron como ensambladoras y con escasos vínculos locales señalados por Doner (2009) ${ }^{6}$. A diferencia de los países que lideraron el flying geese, los núcleos de acumulación de estos no lograron combinar el dinamismo y la endogeneidad, ni tampoco una capacidad estatal comparable -como veremos a continuación-.

La posibilidad de obtener combinadamente estas propiedades en el núcleo de acumulación, por parte de los tres países que formaron la plataforma de integración macro-regional, encuentra como elemento clave la presencia de núcleos de implicación estatal que sometieron a los capitales externos -así como a los propios capitalistas locales- a condiciones estrictas, y a dirigir estratégicamente a los

\footnotetext{
5 La Asociación de Naciones del Sudeste Asiático (Association of Southeast Asian Nations -ASEAN-), es una organización regional de estados del sudeste asiático creada en 1967 y compuesta actualmente por 10 países miembros: Malasia, Indonesia, Filipinas, Brunéi, Vietnam, Camboya, Laos, Myanmar, Singapur, Tailandia. Ver más en http://asean.org/.

6 Las empresas extranjeras que operan en la ASEAN se han trasladado a productos de mayor valor agregado, pero los productores locales participan poco de este valor. En contraste con Corea del Sur, Taiwán y Singapur, las economías de la ASEAN tienden a ser dualistas, con firmas extranjeras que dominan las exportaciones de alta tecnología como ensambladoras, y exhiben pocos vínculos con los productores nacionales de bienes intermedios y de capital. Los efectos indirectos de la tecnología, incluso de los socios compradores o proveedores extranjeros más solidarios, requieren esfuerzos deliberados y sistemáticos. Estos esfuerzos pueden tener que ser estimulados por las recompensas y amenazas de las autoridades públicas -lo que Amsden (2001) llama "reciprocidad"-. Y porque la actualización se basa en múltiples actores como fuentes de información, insumos intermedios y beneficios selectivos, lo que suele implicar esfuerzos colectivos.
} 
Variedades y variaciones de capitalismo en la periferia. América Latina y el este asiático reconsiderados

actores económicos en general (véase Kohli, 2004). La configuración del núcleo de implicación estatal involucra tanto la capacidad de ofrecer protección a ciertos actores económicos, como también su control para evitar que dicha protección adquiriera el carácter frívolo indicado por Fajnzylber (1983), contrario a los intentos de innovación y aprendizaje colectivo, de acuerdo con lo que aluden Chibber (2003) y Woo-Cumings (1999). A través de procesos específicos en el ámbito nacional, los mencionados estados del EA desarrollaron muchas de las propiedades que mencionamos anteriormente como condiciones cruciales de éxito para su núcleo de implicación estatal. Por un lado, como señalan los trabajos de Johnson (1982), Öniş (1991), Chibber (2002, 2003), Kohli (2004) y Chang (2010), estructuras coherentes y burocráticamente calificadas con agencias centralizadas para formular estrategias de acumulación en interacción con el capital local y externo; y, por otro lado, de acuerdo con Zysman (1983), Cho y Kim (1997), Woo-Cumings (1999), Baek (2005) y Kroeber (2011), estrategias que permitieron a las autoridades estatales ejercer influencia sobre las corporaciones a través del control del sector financiero y su capacidad de dirigirlo hacia el sector productivo.

Ahora bien, la presencia de las propiedades señaladas en ambos núcleos les permitió desarrollar un proceso de sinergia virtuosa. El núcleo de implicación estatal logró no solo conformar a los actores capitalistas locales, sino también orientar el desarrollo de sus comportamientos. Al mismo tiempo, la combinación de la forma endógena y y la dinámica del núcleo de acumulación, obtenido desde los procesos de aprendizaje e innovación de esos actores, fue dando la base de sustentación y legitimidad al núcleo de implicación estatal y su acción estratégica.

En AL, por el contrario, y tomando los aportes de Schuldt y Acosta (2006), ambos núcleos, sus propiedades y sus formas de interacción, desarrollaron características con diferencias abrumadoras. En general, el tipo de núcleo de acumulación que prevaleció en la región posee una base altamente concentrada, exógena e incluye una fuerte tendencia a obtener cuasi-rentas derivadas de las ventajas de los recursos naturales antes que en los procesos de aprendizaje colectivo.

La forma fuertemente concentrada de los actores capitalistas locales, aferrada a las ventajas comparativas de los recursos naturales y ajena al riesgo y la innovación, no sufrió alteraciones sino que constituyó la base -limitante- durante la estrategia de sustitución de importaciones desarrollada muy tempranamente en la región. De hecho, como advierten Fajnzylber $(1983,1987)$ y Levy-Orlik (2009), la mayoría de las estrategias de industrialización sustitutiva de importaciones que se persiguieron hasta los años setenta se convirtieron en una especie de proteccionismo generalizado ${ }^{7}$

7 Las políticas proteccionistas en AL se aplicaron al conjunto del sector manufacturero, es decir, un esquema general para productos manufacturados acabados. Las ETN y las empresas nacionales eran igualmente 
y frívolo que favorecía a compañías tanto locales como extranjeras, pero no al desarrollo de una estructura productiva innovadora. El intento de enfrentar los problemas asociados a avanzar sobre la sustitución de las fases más complejas de la industrialización mediante la promoción de la afluencia de capital transnacional, en general, intensificó la heterogeneidad socio-productiva sin contribuir significativamente al dinamismo o la complejidad de los procesos de acumulación locales a partir de procesos de aprendizajes endógenos (Véase Amsden, 2001; 2007; y Sunkel, 1971).

A diferencia de los países que lideraron el proceso de desarrollo en el EA, el núcleo de acumulación resultante en AL se caracterizó por su concentración, careció de dinamismo y exhibió una frágil base endógena, con lo cual su base de aprendizaje e innovación fue insuficiente, y su estructura de actores y sectores centrales encargados de realizarlo fue progresivamente transnacionalizada.

Desde el punto de vista de los resultados, ello trajo efectos debilitadores tanto internos como externos. En el plano interno, una mayor debilidad relativa tanto en la generación como en el control local sobre el excedente generado impuso fuertes limitaciones tanto en los intentos políticos de redistribución como en una posible expansión de la base de acumulación. Externamente, en la capacidad de inserción externa por las vías de las actividades de alto valor, lo cual también forma un requisito para dar sostenibilidad a esos aspectos internos.

Estas características y dinámicas del núcleo de acumulación predominante en AL fomentaron -y, al mismo tiempo, fueron facilitadas por- el surgimiento de una especie de núcleo de implicación estatal con propiedades disímiles a las encontradas en el EA. En AL, no constan trayectorias nacionales en las que el Estado haya podido dirigir desde el combinado proceso de consensualidad y disciplinamiento; como indican Cardoso (1985), Portantiero (1989) y Faletto (1989), aun con un protagonismo creciente durante todo el período de posguerra, fue un actor progresivamente colonizado y capturado a través de los "anillos burocráticos" que expresaban los intereses corporativos tanto del capital local como extranjero. Al amoldamiento organizativo y funcional del Estado a las presiones corporativas que ello representaba, se sumó la necesidad de atender los reclamos redistributivos emanados de la activación cíclica de sectores populares, como lo describe O’Donnell (2009).

elegibles bajo las políticas proteccionistas, y se suponía que las importaciones estarían compuestas por bienes intermedios y de capital, demandados principalmente por las ETN y las empresas públicas. Por lo tanto, la transferencia de tecnología se limitó a un proceso de adaptación y su objetivo fue reducir los costos de producción de los bienes manufacturados privados y finales, mediante subsidios a la importación y precios más bajos de bienes públicos, usualmente utilizados como insumos para las industrias manufactureras privadas (electricidad, por ejemplo). 
Variedades y variaciones de capitalismo en la periferia. América Latina y el este asiático reconsiderados

Producto de esa dinámica, Castellani (2002) observa que el Estado conformó una estructura organizacional altamente fragmentada, incapaz de construir aquellas agencias centralizadas y generadoras de coherencia, demandadas para disciplinar a los actores capitalistas y dar al proceso de acumulación una orientación estratégica hacia el fortalecimiento endógeno y dinámico, como en las experiencias del EA. Esto limitó su capacidad de implementar instrumentos autónomos con los cuales dirigir a los actores económicos, algo que fue reforzado junto con un grado bastante débil de control sobre el sistema financiero -escasamente desarrollado-.

Como resultado de estas propiedades, los núcleos quedaron sujetos a una sinergia negativa, en la cual el núcleo de implicación estatal careció de capacidades para dirigir los núcleos de acumulación hacia sus formas endógenas y dinámicas, mientras que en estos se formó una matriz de actores y comportamientos que obstaculizaron esa capacidad en los núcleos de implicación estatal.

\subsection{Permisividades y viabilidades: presencias divergentes en la configuración de los núcleos}

La conformación y sinergia de esos núcleos y su divergencia entre el EA y AL, como advertimos, no fue resultado de un proceso espontáneo e intra-nacional, sino que tuvo lugar a partir de la diferenciada presencia tanto de factores externos como domésticos advertidos por Beeson (2004) o, en palabras de Jaguaribe (1979), de permisividades externas y viabilidades internas históricamente construidas. Mientras que las permisividades externas aluden a alianzas geopolíticas inter-estatales que, de acuerdo a sus propios intereses, habilitan u obstaculizan estrategias de desarrollo, las viabilidades internas hacen referencia al proceso conflictivo en que Estados y actores del proceso de acumulación disputan internamente su autonomía para consolidar una estrategia de desarrollo. En este sentido, en dependencia a las propiedades antes referenciadas, se conforman relaciones sinérgicas positivas o negativas que marcan la capacidad directiva del núcleo de implicación estatal respecto al núcleo de acumulación, o bien la debilitan frente a la capacidad de los actores y lógicas del mencionado núcleo de acumulación.

Respecto a la permisividad externa, los países destacados del EA contaron con el abrigo de la estrategia geopolítica liderada por EE. UU., como aluden Castells (1992), Evans (1998), Chibber (2003, 2008) y Glassman (2011), el cual los colocaba como aliados dentro de la macro-región. Entre otras cosas, implicaba promover sin obstáculos el fortalecimiento de su núcleo de acumulación que potenció una industrialización sustitutiva y condicionó la inversión extranjera directa, al tiempo que EE. UU. ofrecía el extenso mercado como espacio de realización y pasaje del proceso de sustitución al de exportación. 
En cuanto a la viabilidad interna, los propios capitalistas locales, debilitados después de procesos bélicos destructivos, enfrentaron la necesidad de conformar un escenario / proceso comunitario de desarrollo, lo que alentaba tanto su colaboración o asociación con el Estado, como la aceptación del disciplinamiento impuesto por aquel para lograr esas metas y capitalizar el mercado norteamericano, como observa Chibber $(2003,2008)$. A esa debilidad, se sumaron los procesos de reforma agraria señalados por Kay (2002), pretéritos a la industrialización y funcionales a la ocupación de posguerra, los que, junto a sus efectos redistributivos y sumados a la escasez de recursos naturales, impidieron la consolidación de actores capitalistas concentrados y rentistas con capacidad de bloqueo a las iniciativas estatales y su acción disciplinadora, aspectos indicados en Castells (1992), Pempel (1999), Kay (2002) y Davis (2004). Finalmente, a ello se sumó lo planteado por Deyo (1987) y Castells (1992), referido a la fragilidad organizativa y subalterna de la fuerza de trabajo que no tuvo posibilidad alguna de ejercer presiones para mejorar sus condiciones laborales.

En lo que refiere al núcleo de implicación estatal Kohli (2004) y Vu (2007) marcan que producto, de la tradición Meiji en el caso de Japón, y del linaje colonial de este sobre Corea y Taiwán, así como en propiedades de sus propias elites, se configuraron estados meritocráticos, preparados desde su capacidad técnica y coherencia organizacional centralizada para un proceso de conducción en parte consensuado y -por sobre todo- disciplinario sobre los actores económicos locales estructuradores del núcleo de acumulación (véase Amsden, 1989). En este sentido, Chibber (2003) agrega que el mayor condicionamiento de los capitalistas locales derivados de la reforma agraria y del contexto geopolítico, como la señalada subalternidad y exclusión de la fuerza de trabajo del proceso institucional operaron como habilitantes de la (re)construcción de los estados de posguerra bajo el desarrollo de estas propiedades.

En contraste con el EA, AL desplegó un escenario de viabilidades y permisividades claramente diferentes que impactaron sobre las propiedades de sus núcleos. En el campo de las (in)viabilidades internas, por un lado, Kay (2002) destaca que el limitado alcance de las reformas agrarias dejó inalterado el poder concentrado de los capitalistas locales, a lo que se sumó el poder, también concentrado, de los actores trasnacionales crecientemente presentes a partir de la década de 1950, a medida que se agravaban las condiciones del proceso sustitutivo. Por otro lado, O'Donnell (1973) manifiesta que la presencia de una fuerza de trabajo activada y organizada en diferentes frentes sectoriales y de actividad trasladaba al interior del Estado sus reclamos distributivos obligándolo a mediar en los conflictos con las distintas formas de capital. A diferencia de aquellos países que lideraron el dinamismo del EA, todo ello transformó a estos actores (capital y trabajo) en actores 
que conforman, condicionan y direccionan el Estado, lo que impactó directamente en los núcleos de implicación estatal a través del referido proceso de colonización y copamiento corporativo de sus estructuras. Como resultado de ello, se configuró una matriz de organización y funcionamiento estatal fragmentaria - destacada por Esser (1993) - asentada, a su vez, sobre una herencia de prácticas institucionales históricamente ligadas al patrimonialismo -y el extractivismo-, como revelan Acemoglu y Robinson (2012).

Las inviabilidades internas marcadas anteriormente fueron retroalimentadas desde el punto de vista de las permisividades externas -o intolerancias- de un medio geopolíticamente más inhóspito que el del EA. Ello se debió a la impenetrabilidad de los productos latinoamericanos en el mercado americano, como, así también, de manera concomitante, con la intolerancia de las oligarquías locales para impulsar proyectos de "nacionalismo industrializador", que podían condicionar la integración subordinada e internamente descomplejizadora de los commodities y, como reconoce Fiori (2015), desplegar un proyecto macro-regional contra-hegemónico.

Gráfico 1. Configuración del núcleo de acumulación y de implicación estatal en el Este Asiático

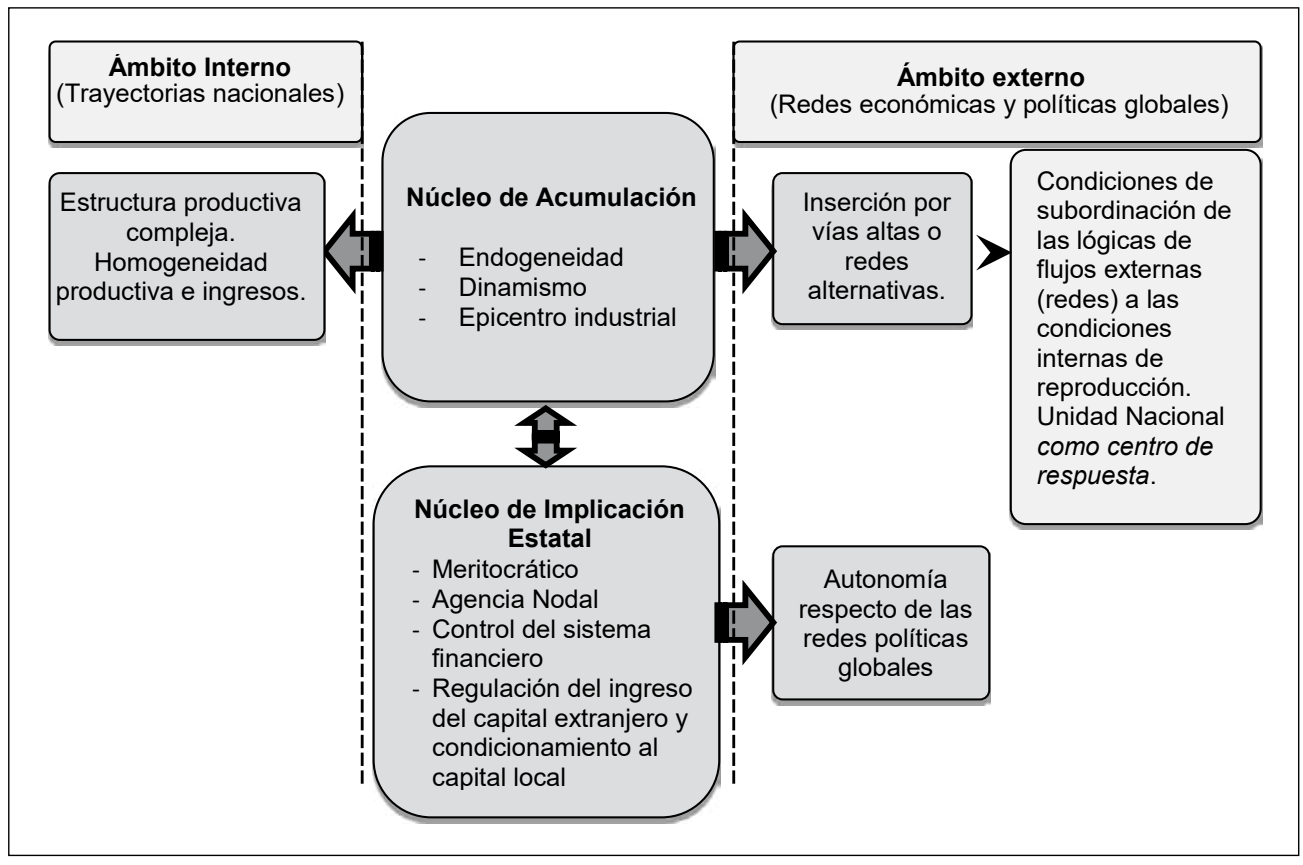

Fuente: elaboración propia 
En resumen, la existencia de inviabilidad interna y carencia de permisividad externa en las trayectorias históricas, y particularmente de la forma de construcción estatal y acumulación industrial en la posguerra, impactaron en las calidades de los núcleos y sus relaciones. Ello dio lugar a estructuras de reproducción interna y performances externos divergentes que explican el diferencial dinamismo del EA y AL - con todas sus especificidades internas- y las variaciones que tuvieron lugar desde la fase del capitalismo monopólico en la periferia.

Gráfico 2. Configuración del núcleo de acumulación y de implicación estatal en América Latina

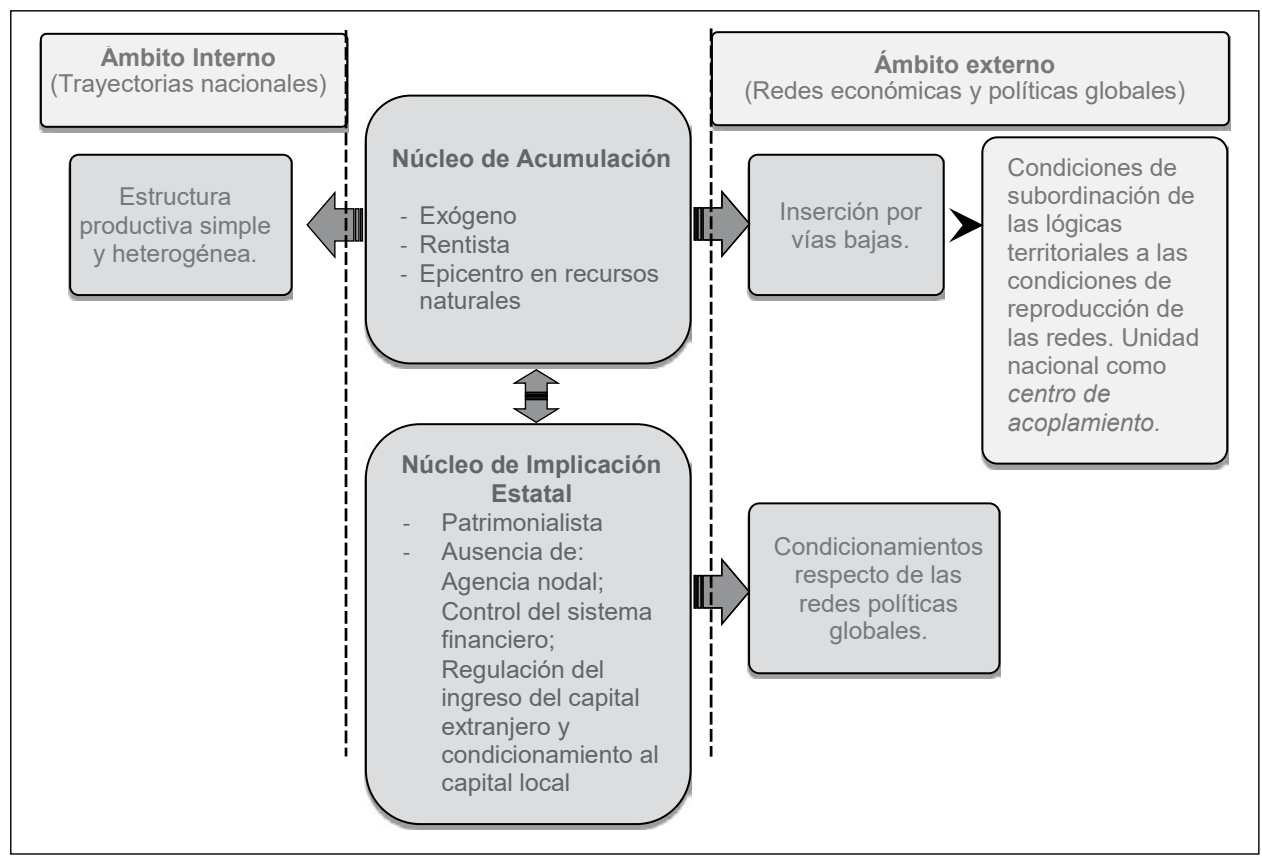

Fuente: elaboración propia

\section{LOS CAMBIOS EN LA FASE GLOBAL DEL CAPITALISMO: DESDE LAS RESPUESTAS DIFERENCIADAS A LA (IN)SOSTENIBILIDAD EN LAS PROPIEDADES DE LOS NÚCLEOS}

A partir de mediados de 1970, la crisis de la fase monopólica dio lugar a un cambio cualitativo del sistema capitalista que impactó tanto en los procesos de producción y realización como de la intervención estatal, es decir, en los ámbitos donde se configuran ambos núcleos.

En lo que respecta al primer aspecto, basado en una revolución tecnológica centrada en la información, las formas nacionalmente centradas del capitalismo monopólico fueron transformadas a partir de la emergencia de las redes econó- 
micas globales, en las que operan decisiones de producción y realización a escala global en tiempo real, como observa Castells (1996). En el interior de ellas, Sassen (2010) y Dicken (2011) destacan que tuvieron lugar múltiples procesos de des / multilocalización de actividades, al tiempo que las Empresas Transnacionales (ETN) recentralizaron el control de los mismos. De acuerdo con Brenner (1997), Cox (1987) y Wade (1990) ello fue viabilizado por una transformación en la geografía y las lógicas de la regulación, que contempló cambios profundos en la organización escalar, así como en el desarrollo de las redes políticas globales con centro en las organizaciones supranacionales (particularmente financieras), y un papel activo de los estados centrales en la formación y contenidos de esas organizaciones. Bajo el liderazgo de estas últimas, las redes políticas globales desplegaron nuevas vinculaciones con los Estados de la periferia y procuraron adecuar su organización y funcionamiento, y compatibilizarlo con el despliegue -subordinador- de las redes económicas globales y las actividades de más alta valorización, cuyos comandos se encuentran a cargo de las ETN en los países centrales.

En ese nuevo escenario, ¿cuáles fueron las variaciones de las trayectorias nacionales y macro-regionales que tuvieron lugar en la periferia a partir de enfrentar estos procesos? Este interrogante y la asimilación de ese cambio cualitativo, desnuda los límites del nacionalismo metodológico que dominó al enfoque de variedades de capitalismo y obliga a superarle al considerar las variaciones capitalistas en la periferia a la luz de esos cambios cualitativos que imponen el funcionamiento de las redes económicas y políticas globales que, por lo indicado, redefinen, pero no alteran las relaciones centrales y periféricas. En el marco de esas redefiniciones, surgen dos aspectos que responden a los interrogantes ya formulados, y que observaremos a continuación:

a. La configuración de los núcleos (sus propiedades y relaciones) desarrollados y consolidados en el EA y AL durante la fase monopólica explican la forma diferencial en que esas macro-regiones reaccionaron y se re-vincularon a las redes económicas y políticas globales.

b. La (in)sostenibilidad intra-nacional de las propiedades de los núcleos y su relación sinérgica a partir del nuevo vínculo con las mencionadas redes económicas y políticas globales.

\subsection{Respuestas diferenciadas en el contexto de la fase globalizada}

En lo que hace al primer aspecto, en el caso de AL Ocampo y Ros (2011) advierten que el proceso de reestructuración global convergió hacia mediados de 1970 con el agotamiento de la estrategia sustitutiva y los límites crecientes del núcleo de im- 
plicación estatal para dar continuidad al proceso industrializador. Ello agudizó la crisis y facilitó el ingreso del capital financiero excedente, dando lugar a un inédito proceso de endeudamiento tomado por estados débiles, insertos en un regresivo estancamiento del proceso de acumulación que se extendió durante toda la década de 1980.

Hacia 1990, con la llegada del Consenso de Washington, la ofensiva del capital financiero y productivo, que controlaba las redes económicas globales, impactó sobre los núcleos de acumulación como en los núcleos de implicación estatal. En cuanto a estos últimos, Ocampo (2011) y Palma (2009) desvelan que fueron drásticamente removidos los procesos regulatorios nacionales montados para desarrollar la sustitución de importaciones. Ffrench-Davis (2005) y Soto (2013) dan cuenta de cómo la desregulación de las cuentas de capital y la penetración extranjera del sistema financiero eliminaron un instrumento fundamental del núcleo de implicación estatal para cualificar el núcleo de acumulación a través de la vinculación del capital financiero hacia el productivo. Como efecto de lo anterior, el núcleo de acumulación profundizó el componente exógeno, así como su falta de dinamismo basada en la ausencia persistente de inversión en el aprendizaje y la innovación (véase Cimoli, 2005), y la creciente presencia de capitales transnacionales en actividades con alta rentabilidad, pero baja complejidad productiva y contenido tecnológico, como indica Arceo (2005).

Observado integralmente AL, la respuesta a la acción de las redes estuvo dominada por un acoplamiento subalterno a las mismas a partir de un cambio profundo del núcleo de implicación estatal, producto de su acondicionamiento a los organismos internacionales y una continuidad en la forma exógena y escasamente dinámica del núcleo de acumulación. Como resultado de ello, y no obstante el ingreso masivo de inversión extranjera directa, Ocampo y Ros (2011) y Arceo (2005) marcan que no solo se produjo una reducción de las tasas de crecimiento en comparación con el período de Industrialización por sustitución de importaciones (ISI) y una desindustrialización prematura de la región, sino que se vieron afectados los planos internos y externo donde se define el desarrollo. Respecto al primero, Portes y Hoffman (2003) advierten que se agravó la heterogeneidad de la estructura socio-productiva así como la prevalencia de una sociedad cada vez más informal, desigual y dualizada; en la dimensión externa, Blyde (2014) considera que se reforzó la inserción subordinada en las redes económicas globales bajo el predominio de la producción de bajo valor agregado.

En cambio, a diferencia de AL, la constitución de las propiedades y la interacción virtuosa de los núcleos durante la fase monopólica en las experiencias del EA 
Variedades y variaciones de capitalismo en la periferia. América Latina y el este asiático reconsiderados

le confirió un poder inmunológico marcadamente divergente para enfrenar la penetración de las redes económicas globales, ya que operaron como centros de respuestas antes que como meros nodos de acoplamiento subordinado como sucedió en AL. El EA, a partir de mantener internamente la dirección del núcleo de implicación estatal a través de su coherencia organizacional y funcional -productiva y financiera-sobre el dinamismo y endogeneidad del núcleo de acumulación, no solo gestó condiciones de inserción externa en procesos y funciones de más alta valorización, señalados por Doner (2009) y Blyde (2014), sino que en el plano interno, y en el contexto de la imposición global del proyecto neoliberal, Jomo (2001) indica que eso facilitó la creación de condiciones de mayor homogeneidad social que trajo aparejada mayor igualdad.

Como ilustra el trabajo de Fernández, Lauxmann y Trevignani (2014), la divergencia entre el EA y AL, no solo es indicativa de que unas trayectorias de desarrollo son más exitosas que otras, sino que, en el marco del más reciente proceso de dinamismo del Sur Global como un todo, la emergencia de condiciones -externas e internas- diferenciadas abre nuevos interrogantes sobre las nuevas asimetrías en lo que tradicionalmente se ha denominado periferia del sistema-mundo. A título ilustrativo, puede mencionarse el desafiante escenario de multipolaridad que se abre con la avasallante irrupción de China que, a juicio de Arrighi (2007), coloca progresivamente al gigante asiático como la "unidad" que disputará el relevo en la hegemonía del nuevo ciclo de acumulación y, siguiendo a Fernández (2013), encuentra en el propio Sur Global un campo de expansión y nuevas formas de subordinación.

\subsection{La (in)sostenibilidad de los núcleos y sus relaciones virtuosas en el EA}

La formación de los núcleos, sus propiedades e interrelaciones en la fase monopólica del capitalismo parecen explicar no solo las diferencias estructurales entre el EA y AL al momento de enfrentar la nueva fase globalizada y la acción penetrante de las redes económicas y políticas globales que la configuran, sino también la excepcional salida de la posición periférica y / o semi-periférica de ese conjunto reducido de países del EA que lideraron la integración macro regional.

Sin embargo, el análisis de las variaciones capitalistas y las trayectorias diferenciadas en la periferia que acabamos de considerar no puede realizarse a partir de una relación unidireccional y estática entre los núcleos y las redes económicas y políticas globales. Por el contrario, se debe notar el marco de relaciones conflictivas y bi-direccionales que se establecen entre los mismos, las que generan cambios que pueden restar sostenibilidad a esa interacción virtuosa de los núcleos - 
observados en el EA y ausentes en AL- a partir de la alteración de las condiciones de permisividades externas y viabilidad interna.

En ese sentido, no obstante los resultados exitosos producto de la sinergia virtuosa de los núcleos, las experiencias analizadas del EA debieron enfrentar un proceso de crisis y reestructuración que horadó tanto la endogeneidad y el dinamismo de los núcleos de acumulación, como la capacidad de dirección de los núcleos de implicación estatal, la que no resultó internamente inofensiva.

En primer lugar, como observa Ross (2008), la crisis financiera y la estanflación se hicieron presentes en Japón hacia finales de 1980 e inicios de 1990, mientras que hacia 1997 el crash monetario y devaluatorio en el sudeste asiático redujo drásticamente las economías de Corea del Sur, Hong Kong, Taiwán, entre otros países de la región. En la gestación de esas crisis, pero, sobre todo, en los cambios sobrevinientes a las mismas operó una fuerte presión por el desmantelamiento de los núcleos de implicación estatal desarrollistas. Estos cambios fueron impulsados progresivamente en Japón y más bruscamente en Corea por las fuerzas neoliberalizadoras dirigidas por las fracciones trasnacionalizadas del capital que controlan las redes económicas globales, así como por los organismos internacionales que controlan las redes políticas globales (véase Schoppa, 2006; Estévez-Abe, 2008; Crotty y Lee, 2005; y Lim y Jang, 2006).

Esa presión para desmantelar los núcleos no fue ciertamente unicausal. En primer lugar, hubo un retiro visible de la permisividad externa dada por la geopolítica americana de posguerra. Después de la guerra fría, EE. UU. se dirigió, por un lado, hacia la protección de sus mercados y la reducción de las libertades del EA advertidas en Bello (1999); y por otro lado, a facilitar la ofensiva de sus propios capitales productivos y, sobre todo, financieros en esos escenarios (véase Gowan, 1999; y Ji, 2013). Por su parte, en el interior de los propios socios del flying geese, Hart-Landsberg y Burkett (2001) y Ji (2013) argumentan que comenzaron a recelarse las transferencias cooperativas de conocimiento y a valorizarse los riesgos de los catching up.

El elemento estructurador fue la nueva lógica acumulativa de las fracciones del capital global y el intento de las mismas de reposicionarse y recomponer su control de los procesos de acumulación, particularmente a través del papel central y creciente de sus segmentos -y formas- financieros. Bajo esas nuevas lógicas, y bajo una fuerte presión liberalizadora sobre el intervencionismo del núcleo de implicación estatal, a criterio de Jomo $(2006,2003)$ visible en todo el EA desde 1980 , Crotty y Lee (2005), y Wade y Veneroso (1998) argumentan que dichas fracciones pugnaron por el desplazamiento del control estatal sobre el sistema financiero y su reemplazo por un sistema desregulado, guiado por los criterios del mercado de 
Variedades y variaciones de capitalismo en la periferia. América Latina y el este asiático reconsiderados

capitales. En su concreción, como muestran los trabajos de Evans (1998), Chang y Evans (1999), Crotty y Kang-Kook (2001), Crotty y Lee (2005) y Park (2013), junto al poder penetrante de esos actores y lógicas financieras incorporadas a las redes económicas globales a partir de la presión "liberalizadora", actuó un cambio en las condiciones de viabilidad internas generadas por el plegamiento a ese proceso de los grupos locales -concentrados, progresivamente trasnacionalizados-, crecientemente independizados de la "asistencia consensual y disciplinaria del Estado" (algo muy visible en Corea).

En este sentido, como marcan Crotty y Lee (2005), Jomo (2006) y Doucette (2009), el escenario de permisividad y viabilidad de posguerra viró hacia uno de fuertes presiones trasnacionales por el desmantelamiento de aquellos mecanismos que, a través de la intervención estratégica (consensual y disciplinaria) del núcleo de implicación estatal aseguraron, aún después de la crisis capitalista de finales de 1960, un proceso de crecimiento que distinguió a la región del EA.

Si bien el desmantelamiento no operó automática ni generalizadamente, por cuanto convivió largo tiempo con el rol proactivo del Estado, como señalaron Jomo, (2003) y Yeung (2000), la potencia del penetrante capital trasnacional asociado al globalizado capital "vernáculo", contenía una nueva lógica - de matriz financiera- sustentada en la progresiva imposición de prácticas cortoplacistas, propias de la movilidad ganada por el capital, como describen Epstein, Sclesinger y Vernengo (2014).

Estas transformaciones contribuyeron a redefinir el vínculo virtuoso existente entre el Estado y los grupos empresariales, sustentado en un capital paciente formado por la dirección estatal y un sistema financiero basado en bancos (estatales) que garantizaba los procesos de aprendizaje e innovación productivos y, con ello, el impresionante proceso de desarrollo de posguerra (ver Crotty y Lee, 2002). Como aseguran Wade y Veneroso (1998) y Crotty y Lee (2002), esa redefinición encontró respaldo en los organismos internacionales, particularmente el FMI, que alentaron activamente la visión de la necesidad de afirmar la desregulación y la des-implicación estatal para desactivar las ineficiencias y predisposiciones a la corrupción que formó parte del "capitalismo de amigos" (crony capitalism) indicado en Lee (1999), Lim (1997) y Rosenberger (1997). Siguiendo a Crotty y Kang-Kook (2001) y Thurbon (2003), el argumento encontró eco en el interior de la propia estructura estatal de donde surgió un relato crítico sobre la ineficiencia de la "sobreinversión" y los efectos corrosivos de las prácticas de corrupción que tenían lugar en la interacción del Estado con los capitales privados, imputables a una estructura vertical -y autoritaria- para explicar las crisis, como también advierte Ji (2013). 
La penetración conjunta de capital trasnacional a través de las redes económicas globales y de los organismos internacionales a través de las redes políticas globales, operó re-alimentariamente sobre el núcleo de acumulación y el núcleo de implicación estatal sobre dos aspectos sustantivos de su sinergia virtuosa de posguerra: el dinamismo y la endogeneidad. El primero, a partir del socavamiento del "capital paciente" sobre el cual maceran los procesos colectivos de aprendizaje, amenazados crecientemente por el rentismo de la financiación cortoplacista. El segundo, progresivamente debilitado por la trasnacionalización del aparato financiero y la exogeneización del capital trasnacional originado en los grupos capitalistas locales.

Esa afección en el núcleos de acumulación, a su vez, fue facilitada por -pero también generadora de- un debilitamiento de la capacidad del núcleo de implicación estatal para orientar las propiedades del núcleo de acumulación, a través del desplazamiento / desmantelamiento de sus estructuras centralizadas de planificación y disciplinamiento (Henderson, 2011), hacia la creación de un marco conceptual-ideológico desde los propios agentes estatales que fue compatible con las formas adoptadas por el núcleo de acumulación y promocionadas por los organismos internacionales. Paradójicamente, montado sobre la necesidad de una intervención activa del Estado para su concreción advertida por Kiely $(1998)^{8}$, según Crotty y Lee (2002) y Chang y Evans (1999) ese marco vino a cuestionar su rol de director estratégico del núcleo de acumulación en un escenario de distanciamiento de los actores dominantes del mismo que, siguiendo a Henderson y Hulme (2002), terminó de resquebrajar su autonomía y readecuar su implicación a las lógicas reproductivas cortoplacistas de las fracciones transnacionalizadas del capital. De este modo, el núcleo de implicación estatal resultó debilitado en su capacidad de control directo sobre el capital financiero ya que, como muestran Crotty y Lee (2005), accedió a las presiones por flexibilización de la relación laboral y el aliento al posicionamiento del capital externo en el mercado local.

En suma, el análisis de las variaciones del capitalismo en la periferia, muestra que aquellos elementos virtuosos de los núcleos y sus relaciones resultan inestables y sujetos a la propia lógica contradictoria del capitalismo. Tachibanaki (2006) y Shin (2010) sostienen que los cambios surgidos de esa inestabilidad no resultan inocuos desde el punto de vista de los efectos sociales, advirtiéndose claramente un proceso de desigualación y precarización de la fuerza de trabajo en los países insignia del desarrollo del EA, como Japón y Corea.

8 Como bien indica Kiely (1998, p. 75), "El Estado es visto como el problema-interviene demasiado. También es visto como la solución - debe reformarse a sí mismo con el fin de permitir actividades de creación de riqueza. Pero, si los estados son puramente egoístas, entonces ¿por qué los funcionarios estatales deberían llevar a cabo las reformas necesarias?". 


\section{CONCLUSIONES}

El presente trabajo se focalizó en analizar las divergencias macro-regionales en el heterogéneo Sur Global, no solo para resaltar sus diferentes trayectorias nacionales y macro regionales respecto a su variación en su inserción global, sino también para hacer más complejo el trato estático, descontextualizado, mono-escalar y nacionalista metodológico del enfoque de variedades de capitalismo.

En esa tarea, como puente de intermediación entre ambos enfoques y como base teórica conceptual para el análisis de las trayectorias históricas de las dos macro-regiones, se introdujeron los conceptos de núcleo de acumulación y núcleo de implicación estatal. Procuramos mostrar la utilidad de estos conceptos para comprender los fundamentos de la lucha desigual sobre el control de las funciones de mayor valorización dentro de las redes económicas globales, así como las diferentes capacidades de los Estados para controlar, dirigir y disciplinar estratégicamente al capital en esa lucha. Al salvar las especificidades nacionales, hemos procurado dar cuenta de ello a través de un análisis de las macro-regiones del EA y AL en el que dichos conceptos permiten dilucidar el modo en que las características económicas e institucionales afectan virtuosamente la producción de variaciones capitalistas.

En este sentido, hemos argumentado que la construcción de los núcleos de acumulación y núcleos de implicación estatal solo puede ser entendida en el marco de su relación dialéctica con las estructuras y dinámicas internas (asociados a la estructura del capital, el poder del trabajo y la trayectoria institucional), y las dinámicas globales enmarcadas por las redes económicas y políticas. En función de ello, la fortaleza endógena de los núcleos de acumulación y su maleabilidad desde los núcleos de implicación estatal puede ser lograda, particularmente en los contextos periféricos, atendiendo tanto a la permisividad de los actores globales por un lado, y -fundamentalmente- por las condiciones de viabilidad de su propia trayectoria histórica y calidad del núcleo de implicación estatal, por otro. Por lo tanto, la interacción de los núcleos con el marco geoeconómico y geopolítico da cuenta de la condición de permisividad (otorgada a los países del EA en el contexto la Guerra fría) o bien la inhabilitación (para el caso de AL) al momento de alterar sus respectivas trayectorias nacionales y / o macro regionales.

Sin embargo, como señalamos en la última parte de este trabajo, y como una de las advertencias clave para considerar estos procesos, remarcamos que las relaciones entre los núcleos y las redes económicas y políticas globales no deben considerarse unidireccional ni estáticamente. Curiosamente, en los últimos años el EA ha mostrado un claro retroceso en la configuración endógena de los núcleos de acumulación en varios de sus países miembros (particularmente, en Corea del 
Sur), y con ello un debilitamiento del núcleo de implicación estatal en la capacidad de dirigirlo. Como resultado de fuertes presiones desreguladoras y la pérdida del control estatal sobre el sector financiero (en buena medida, debido a la progresiva penetración de los organismos internacionales), así como la pérdida gradual del poder disciplinante que ejercía el Estado sobre los grupos empresariales, el núcleo de implicación estatal se encontró con núcleos de acumulación cada vez más trasnacionalizados y menos dependientes de su dirección y apoyo.

\section{BIBLIOGRAFÍA}

Acemoglu, Daron y Robinson, James (2012). Why nations fail: The origins of power, prosperity, and poverty. New York: Crown Business, 546p.

Akamatsu, Kaname (1961). A theory of unbalanced growth in the world economy. En: Weltwirtschaftliches Archiv, Vol. 86, No. 2, p. 192-215.

Akamatsu, Kaname (1962). A historical pattern of economic growth in developing countries. En: The Developing Economies, Vol. 1, No. 1, p. 3-25.

Amsden, Alice (1989). Asia's Next Giant. South Korea and Late Industrialization. Nueva York: Oxford University Press, 400p.

Amsden, Alice (2001). The rise of "The Rest". Challenges to the West from Late-Industrializing Economies. Nueva York: Oxford University Press, 416p.

Amsden, Alice (2007). Escape from empire: the developing world's journey through heaven and hell. Cambridge Cambridge University Press, 209p.

Arceo, Enrique (2005). El impacto de la globalización en la periferia y las nuevas y viejas formas de la dependencia en América Latina. En: Cuadernos del CENDES, Vol. 22, No. 60, p. 25-61.

Arrighi, Giovanni (1994). The long twentieth century: Money, power, and the origins of our times. New York: Verso, 400p.

Arrighi, G. (2007). Adam Smith en Pekín: orígenes y fundamentos del siglo XXI. Madrid: Akal, 432p.

Baek, Seung-Wook (2005). Does China follow "the East Asian development model"? En: Journal of Contemporary Asia, Vol. 35, No. 4, p. 485-498.

Beeson, Mark (2004). The rise and fall (?) of the developmental state: The vicissitudes and implications of East Asian interventionism, p. 29-40. En: Linda Low (Ed.), Developmental states: relevancy, redundancy or reconfiguration. New York: Nova Science Publishers, 240p.

Bello, Walden (1999). Dark Victory: The United States and Global Poverty. London: Pluto Press, $172 \mathrm{p}$.

Blyde, Juan (Ed.) (2014). Fábricas Sincronizadas. Washington: Banco Interamericano de Desarrollo, 209p.

Boschi, Renato Raul (2011). Variedades de capitalismo, política e desenvolvimento na América Latina. Río de Janeiro: Editora UFMG, 374p. 
Variedades y variaciones de capitalismo en la periferia. América Latina y el este asiático reconsiderados

Brenner, Neil (1997). Global, fragmented, hierarchical: Henri Lefebvre's geographies of globalization. En: Public Culture, Vol. 10, No. 1, p. 135-167.

Cardoso, Fernando Henrique (1972). Estado y sociedad en América Latina. Buenos Aires: Nueva Visión, 250p.

Carroll, William y Carson, Colin (2003). Forging a new hegemony? The role of transnational policy groups in the network and discourses of global corporate governance. En: Journal of World-Systems Research, Vol. 9, No. 1, p. 67-102.

Castellani, Ana (2002). La gestión estatal durante los regímenes políticos burocrático-autoritarios. El caso argentino entre 1967 y 1969. En: Sociohistórica, No. 11-12, p. 35-68.

Castells, Manuel (1992). Four Asian Tigers with a dragon head: a comparative analysis of the state, economy and society in the Asian Pacific Rim, p. 33-70. En: Richard Appelbaum y Jeffrey Henderson (Eds.), State and Development in the Asian Pacific Rim. London: Sage, 320p.

Castells, Manuel (1996). The rise of the network society (Vol. 1). The information age: economy, society, and culture. Oxford: Blackwell, 624p.

Chang, Ha-Joon (2010). How to 'do'a developmental state: political, organisational and human resource requirements for the developmental state, p. 82-96. En: Omano Edigheji (Ed.), Constructing a democratic developmental state in South Africa: potentials and challenges. Cape Town: HSRC Press, 326p.

Chang, Ha-Joon y Evans, Peter (1999). The role of institutions in economic change, p. 99-129. En: Silvana de Paula y Gary Dymski (Eds.), Reimagining growth. Towards a renewal of development theory. London: Zed Book, 320p.

Cheng, Lu-Lin y Gereffi, Gary (1994). The informal economy in East Asian development. En: International Journal of Urban and Regional Research, Vol. 18, No. 2, p. 194-219.

Chibber, Vivek (2002). Bureaucratic Rationality and the Developmetal State. En: American Journal of Sociology, Vol. 107, No. 4, p. 951-988.

Chibber, Vivek (2003). Locked in place: State-building and late industrialization in India. Princeton: Princeton University Press, 355p.

Chibber, Vivek (2008). ¿Revivir el Estado desarrollista? El mito de la "Burguesía Nacional". En: Documentos y Aportes en Administración Pública y Gestión Estatal, Vol. 8, No. 11, p. 7- $\overline{34}$.

Cho, Yoon-Je y Kim, Joon-Kyung (1997). Credit policies and the industrialization of Korea (Vol. Korea Development Institute). Seoul: World Bank Publications, 160p.

Cimoli, Mario (2005). Heterogeneidad estructural, asimetrías tecnológicas y crecimiento en América Latina. Santiago, Chile: Cepal/BID, 162p.

Cox, Robert (1987). Production, power, and world order: Social forces in the making of history. New York: Columbia University Press, 500p.

Crotty, James y Kang-Kook, Lee (2001). Economic performance in post-crisis Korea: A critical perspective on neoliberal restructuring. En: Seoul Journal of Economics, Vol. 14, No. 2, p. $183-242$. 
Crotty, James y Lee, Kang-Kook (2002). Is financial liberalization good for developing nations? The case of South Korea in the 1990s. En: Review of Radical Political Economics, Vol. 34, No. 3, p. 327-334.

Crotty, James y Lee, Kang-Kook (2005). From East Asian "miracle" to neo-liberal "mediocrity": the effects of liberalization and financial opening on the post-crisis Korean economy. En: Global Economic Review, Vol. 34, No. 4, p. 415-434.

Davis, Diane (2004). Discipline and development: middle classes and prosperity in East Asia and Latin America. Cambridge Cambridge University Press, 436p.

Deyo, Frederic (1987). State and labor: Modes of political exclusion in East Asian development, p. 182-202. En: Frederic Deyo (Ed.), The political economy of the new Asian industrialism. Ithaca: Cornell University Press, 254p.

Dicken, Peter (2011). Global shift: Mapping the changing contours of the world economy. New York: The Guilford Press, 625p.

Doner, Richard (2009). The politics of uneven development: Thailand's economic growth in comparative perspective. New York: Cambridge University Press, 369p.

Doucette, Jamie (2009). The postdevelopmental state: The reconfiguration of political space and the politics of economic reform in South Korea. Tesis doctoral. Vancouver: University of British Columbia, 336p.

Epstein, Gerald A, Sclesinger, Tom y Vernengo, Matias (2014). Banking, monetary policy and the political economy of financial regulation: Essays in the tradition of Jane D'Arista. Cheltenham y Northampton: Edward Elgar, 392p.

Esser, Klaus (1993). América Latina. Industrialización sin visión. En: Nueva Sociedad, No. 125, p. 27-46.

Estévez-Abe, Margarita (2008). Welfare and capitalism in postwar Japan (Vol. New York): Cambridge University Press, 360p.

Evans, Peter (1998). Alternativas al Estado desarrollista. Lecciones de la crisis de Asia Oriental. En: Nueva Sociedad, No. 155, p. 143-156.

Fajnzylber, Fernando (1983). La Industrialización trunca de América Latina. México D.F.: Editorial Nueva Imagen, 416p.

Fajnzylber, Fernando (1987). Reflexiones sobre las particularidades de América Latina y el sudeste asiático y sus referencias en el mundo industrializado. En: Investigación Económica, Vol. 46, No. 180, p. 63-109.

Faletto, Enzo (1989). La especificidad del Estado en América latina. En: Revista de La Cepal, No. 38, p. 69-87.

Fernandez, Victor; Lauxmann, Carolina y Trevignani, Manuel (2014). Emergencia del Sur Global. Perspectivas para el desarrollo de la periferia latinoamericana. En: Economia e Sociedade, Vol. 23, No. 3, p. 611-643.

Fernández, Víctor Ramiro (2010). Desarrollo regional bajo transformaciones trans-escalares ¿Por qué y cómo recuperar la escala nacional?, p. 301-341. En: Víctor Ramiro Fernández y Carlos 
Variedades y variaciones de capitalismo en la periferia. América Latina y el este asiático reconsiderados

Brandão (Eds.) Escalas y políticas del desarrollo regional. Desafíos para América Latina. Buenos Aires: Editorial Miño y Dávila, 352p.

Fernández, Víctor Ramiro (2013). Doble amenaza, doble debilidad un mismo desafío. Latinoamérica ante la crisis del centro y la desigual emergencia del sur global. Documento de Trabajo del IIETE. Instituto de Investigación Estado, Territorio y Economía. Universidad Nacional del Litoral. Santa Fe.

Fernández, Víctor Ramiro y Alfaro, María Belén (2011). Ideas y políticas del desarrollo regional bajo variedades de capitalismo: contribuciones desde la periferia. En: Revista Paranaense de Desenvolvimento, No. 120, p. 57-99.

Fernández, Víctor Ramiro y Bazza, Alcides (2016). Repensando las Variedades de Capitalismo desde la Periferia. En: Desenvolvimento Em Questão, Vol. 14, No. 35, p. 5-34.

Ffrench-Davis, Ricardo (2005). Reforming Latin America's Economies. After Market Fundamentalism. New York: Palgrave Macmillan, 270p.

Fiori, José Luís (2015). História, estratégia e desenvolvimento: para uma geopolítica do capitalismo. São Paulo: Editorial Boitempo, 277p.

Gereffi, Gary (1989). Rethinking development theory: Insights from East Asia and Latin America. En: Sociological Forum, Vol. 4, No. 4, p. 505-533.

Glassman, Jim (2011). The geo-political economy of global production networks. En Geography Compass, Vol. 5, No. 4, p. 154-164.

Gowan, Peter (1999). The global gamble: Washington's Faustian bid for world dominance. London: Verso, 336p.

Hall, Peter y Soskice, David (2001). An Introduction to Varieties of Capitalism, p. 1-70. En: Peter Hall y David Soskice (Eds.), Varieties of Capitalism. The Institutional Foundations of Comparative Advantage. Oxford: Oxford University Press, 560p.

Hart-Landsberg, Martin y Burkett, Paul (2001). Economic crisis and restructuring in South Korea: Beyond the free market-statist debate. En: Critical Asian Studies, Vol. 33, No. 3, p. 403-430.

Henderson, Jeffrey (2011). East Asian transformation: on the political economy of dynamism, governance and crisis. London: Routledge, 184p.

Henderson, Jeffrey y Hulme, David (2002). Globalization, national economic governance and poverty elimination: Insights from East Asia and Eastern Europe. Final Report to the Department for International Development. (Globalisation and Poverty Programme), Project R7861.

Jaguaribe, Helio (1979). Autonomía periférica y hegemonía céntrica. En: Estudios Internacionales, Vol. 12, No. 46, p. 91-130.

Jessop, Bob (2015). Comparative Capitalisms and/or Variegated Capitalism, p. 65-82. En: Matthias Ebenau, Ian Bruff y Christopher May (Eds.). New Directions in Comparative Capitalisms Research: Critical and Global Perspectives. London: Palgrave Macmillan, 252p.

Ji (2013). The Fall of the Developmental State and the Rise of the Neoliberal State in South Korea: Transformations in Historical, Geographical, and Social Relations, p. 89-134. En: VV.AA. (Ed.), Geo-political Economies of East Asia. Re-locating East Asian Developmental States in their Transnational and Local Contexts. Seoul: Seoul National University Asia Center, 420p. 
Johnson, Chalmers (1982). MITI and the Japanese miracle: the growth of industrial policy: 19251975. Stanford: Stanford University Press, 409p.

Jomo, Kwame (2001). Globalisation, liberalisation, poverty and income inequality in Southeast Asia. OECD Development Centre Working Papers, No. 185, 43p.

Jomo, Kwame (2003). Globalization, liberalization and equitable development: lessons from East Asia. Ginebra: United Nations Research Institute for Social Development, Overarching Concerns Paper, No. 3, 35p.

Jomo, Kwame (2006). Growth with equity in East Asia? En: DESA Working Paper No 33, Department of Economic and Social Affairs of United Nations, Nwe York, 54p.

Kasahara, Shigehisa (2004). The Flying Geese Paradigm: A critical study of its application to East Asian regional development. UNCTAD Discussion Papers, No. 169, Ginebra, 34p.

Kay, Cristóbal (2002). Reforma agraria, industrialización y desarrollo: ¿ Por qué Asia Oriental superó a América Latina? En: Debate Agrario, No. 34, p. 45-94.

Kiely, Ray (1998). Neo liberalism revised? A critical account of World Bank concepts of good governance and market friendly intervention. En: Capital \& Class, Vol. 22, No. 1, p. 63-88.

Kohli, Atul (2004). State-directed development: political power and industrialization in the global periphery. Cambridge: Cambridge University Press, 480p.

Kroeber, Arthur (2011). Developmental dreams: Policy and reality in China's economic reforms, p. 44-65. En: Scott Kennedy (Ed.), Beyond the Middle Kingdom: Comparative perspectives on China's capitalist transformation. Stanford: Stanford University Press, 280p.

Lee, Eddy (1999). The debate on the causes of the Asian crisis: Crony capitalism versus international system failure. En: International Politics and Society, No. 2, p. 162-167.

Levy, David (2008). Political Contestation in Global Production Networks. En: Academy of Management Review, Vol. 33, No. 4, p. 943-962. Doi: http://dx.doi.org/10.5465/AMR.2008.34422006

Levy-Orlik, Noemi (2009). Protectionism and industrialization: a critical assessment of the Latin American industrialization period. En: Revista de Economia Política, Vol. 29, No. 4, p. 436-453.

Lim, Hyun-Chin y Jang, Jin-Ho (2006). Neo-liberalism in post-crisis South Korea: Social conditions and outcomes. En: Journal of Contemporary Asia, Vol. 36, No. 4, p. 442-463.

Lim, Linda (1997). The Southeast Asian currency crisis and its aftermath. En Journal of Asian Business, Vol. 13, No. 4, p. 65-83.

Medeiros, Carlos Aguiar de (2010). Instituições e desenvolvimento econômico: uma nota crítica ao" nacionalismo metodológico". En Economia e Sociedade, Vol. 19, No. 3, p. 637-645.

Ocampo, José (2011). Seis décadas de debates económicos latinoamericanos. En: Initiative for Policy Dialogue, $25 \mathrm{p}$.

Ocampo, José y Ros, Jaime (2011). Shifting paradigms in Latin America's economic development, p. 4-25. En José Ocampo y Jaime Ros (Eds.), The Oxford Handbook of Latin American Economics. Oxford: Oxford University Press, 896p. 
Variedades y variaciones de capitalismo en la periferia. América Latina y el este asiático reconsiderados

O'Donnell, Guillermo (1973). Modernization and bureaucratic-authoritarianism: Studies in South American politics. Berkeley: University of California Press, 219p.

O’Donnell, Guillermo (2009). El Estado burocrático autoritario 1966-1973: triunfos, derrotas y crisis. Buenos Aires: Prometeo, 499p.

Öniş, Ziya (1991). The logic of the developmental state. En: Comparative Politics, Vol. 24, No. 1, p. $109-126$.

Ozawa, Terutomo (2002). The "hidden" side of the "flying-geese" catch-up model: Japan's dirigiste institutional setup and a deepening financial morass. En: Journal of Asian Economics, Vol. 12, No. 4, p. 471-491.

Ozawa, Terutomo (2011). The (Japan-born) 'flying-geese' theory of economic development revisited-and reformulated from a structuralist perspective. En: Global Policy, Vol. 2, No. 3, p. $272-285$.

Palma, José Gabriel (2009). The revenge of the market on the rentiers. Why neo-liberal reports of the end of history turned out to be premature. En: Cambridge Journal of Economics, Vol. 33, No. 4, p. 829-869.

Park, S.J. (2013). Developmental state in Korea (60-70ties) revisited: Institution-building for the making of "coordinated market. En: Ordnungspolitische Diskurse, Working Paper, No. 2013 02, 30p.

Peck, Jamie y Theodore, Nik (2007). Variegated capitalism. En: Progress in Human Geography, Vol. 31, No. 6, p. 731 772. Doi: http://dx.doi.org/10.1177/0309132507083505

Pempel, Thomas J (1999). The developmental regime in a changing world economy, p. 137-181. En: Meredith Woo-Cummings (Ed.), The developmental state. Ithaca and London: Cornell

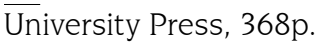

Portantiero, Juan Carlos (1989). La múltiple transformación del Estado latinoamericano. En: Nueva sociedad, No. 104, p. 88-94.

Portes, Alejandro y Hoffman, Kelly (2003). La estructura de clases en América Latina: composición y cambios durante la era neoliberal. En: Desarrollo Económico, Vol. 43, No. 171, p. 355-387. Doi: http://dx.doi.org/10.2307/3455 $\overline{890}$

Prebisch, Raúl (1981). Capitalismo periférico. Crisis y transformación. México D.F., Fondo de Cultura Económica, 344p.

Prebisch, Raúl (1986). El desarrollo económico de la América Latina y algunos de sus principales problemas. En: Desarrollo Económico, Vol. 26, No. 103, p. 479-502.

Rosenberger, Leif (1997). Southeast Asia's currency crisis: a diagnosis and prescription. En: Contemporary Southeast Asia, Vol. 19, No 3, p. 223.

Ross, John (2008). India and China's challenge in the current economic crisis. Key Trends in Globalisation: 20 years of accurate predictions on China and the world economy. 30 de noviembre.

Sassen, Saskia (2010). Global inter-city networks and commodity chains: any intersections? En: Global Networks, Vol. 10, No. 1, p. 150-163. 
Schneider, Ben Ross (2009). Hierarchical market economies and varieties of capitalism in Latin America. En: Journal of Latin American Studies, Vol. 41, No. 03, p. 553-575.

Schneider, Ben Ross (2013). Hierarchical Capitalism in Latin America. Cambridge: Cambridge University Press, 262p.

Schneider, Ben Ross y Soskice, David (2009). Inequality in developed countries and Latin America: coordinated, liberal and hierarchical systems. En: Economy and society, Vol. 38, No. 1, p. 17-52.

Schoppa, Leonard (2006). Race for the Exits. The Unraveling of Japan's System of Social Protection. Ithaca: Cornell University Press, 272p.

Schuldt, Jürgen y Acosta, Alberto (2006). Petróleo, rentismo y subdesarrollo: ¿̇una maldición sin solución? En: Nueva sociedad, No. 204, p. 71-89.

Shin, Kwang-Yeong (2010). Globalisation and the working class in South Korea: Contestation, fragmentation and renewal. En: Journal of Contemporary Asia, Vol. 40, No. 2, p. 211-229.

Soto, Roberto (2013). América Latina: Entre la financiarización y el financiamiento productivo. En: Problemas del desarrollo, Vol. 44, No. 173, p. 57-78.

Sunkel, Osvaldo (1971). Desarrollo, subdesarrollo, dependencia, marginación y desigualdades espaciales; hacia un enfoque totalizante. En: Investigación Económica, Vol. 31, No. 121, p. 23-77.

Tachibanaki, Toshiaki (2006). Inequality and poverty in Japan. En: Japanese Economic Review, Vol. 57, No. 1, p. 1-27.

Thurbon, Elizabeth (2003). Ideational inconsistency and institutional incapacity: Why financial liberalisation in South Korea went horribly wrong. En: New Political Economy, Vol. 8, No. 3, p. 341-361.

Vu, Tuong (2007). State formation and the origins of developmental states in South Korea and Indonesia. En: Studies in comparative international development, Vol. 41, No. 4, p. 27-56.

Wade, Robert (1990). Governing the market: Economic theory and the role of government in East Asian industrialization. Princeton: Princeton University Press, 456p.

Wade, Robert y Veneroso, Frank (1998). The Asian crisis: the high debt model versus the Wall Street-Treasury-IMF complex. En: New Left Review, No. 228, p. 3-23.

Woo-Cumings, Meredith (1999). The developmental state: Cornell University Press, 368p.

Yeung, Henry Wai-chung (2000). State intervention and neoliberalism in the globalizing world economy: lessons from Singapore's regionalization programme. En: The Pacific Review, Vol. 13, No. 1, p. 133-162.

Zysman, John (1983). Governments, markets, and growth: financial systems and the politics of industrial change. Ithaca: Cornell University Press, 358p. 